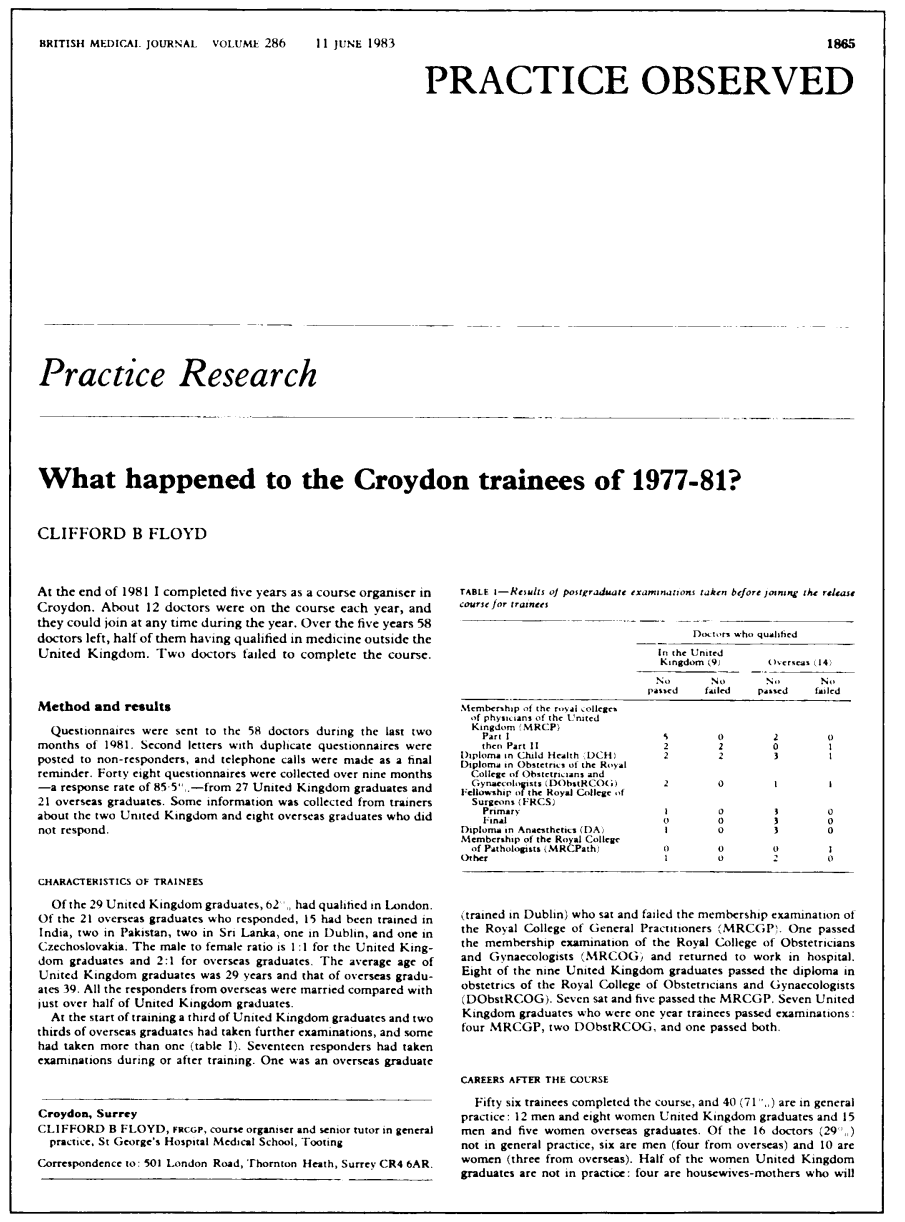

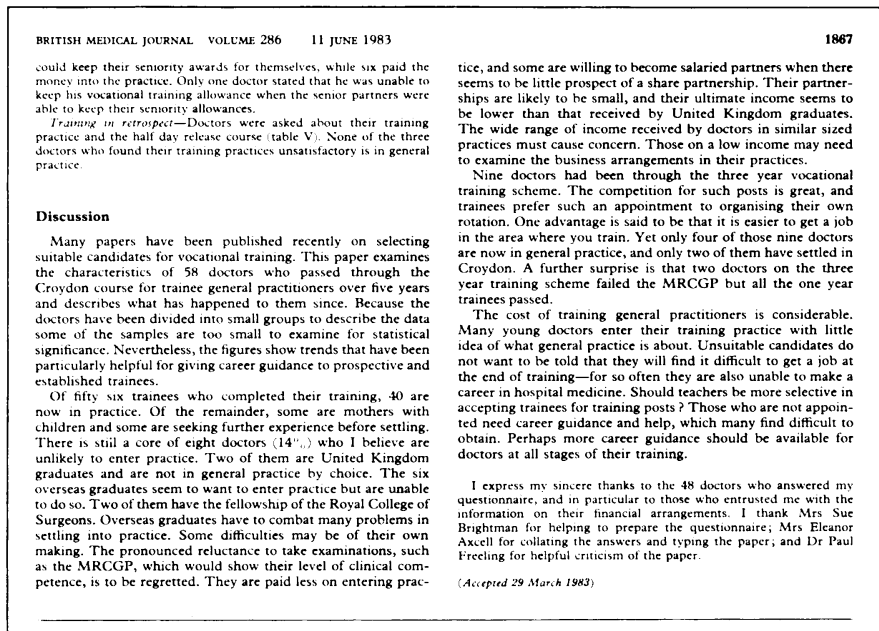

\section{Training in General Practice}

\section{How to interview candidates}

BARBARA J COHEN
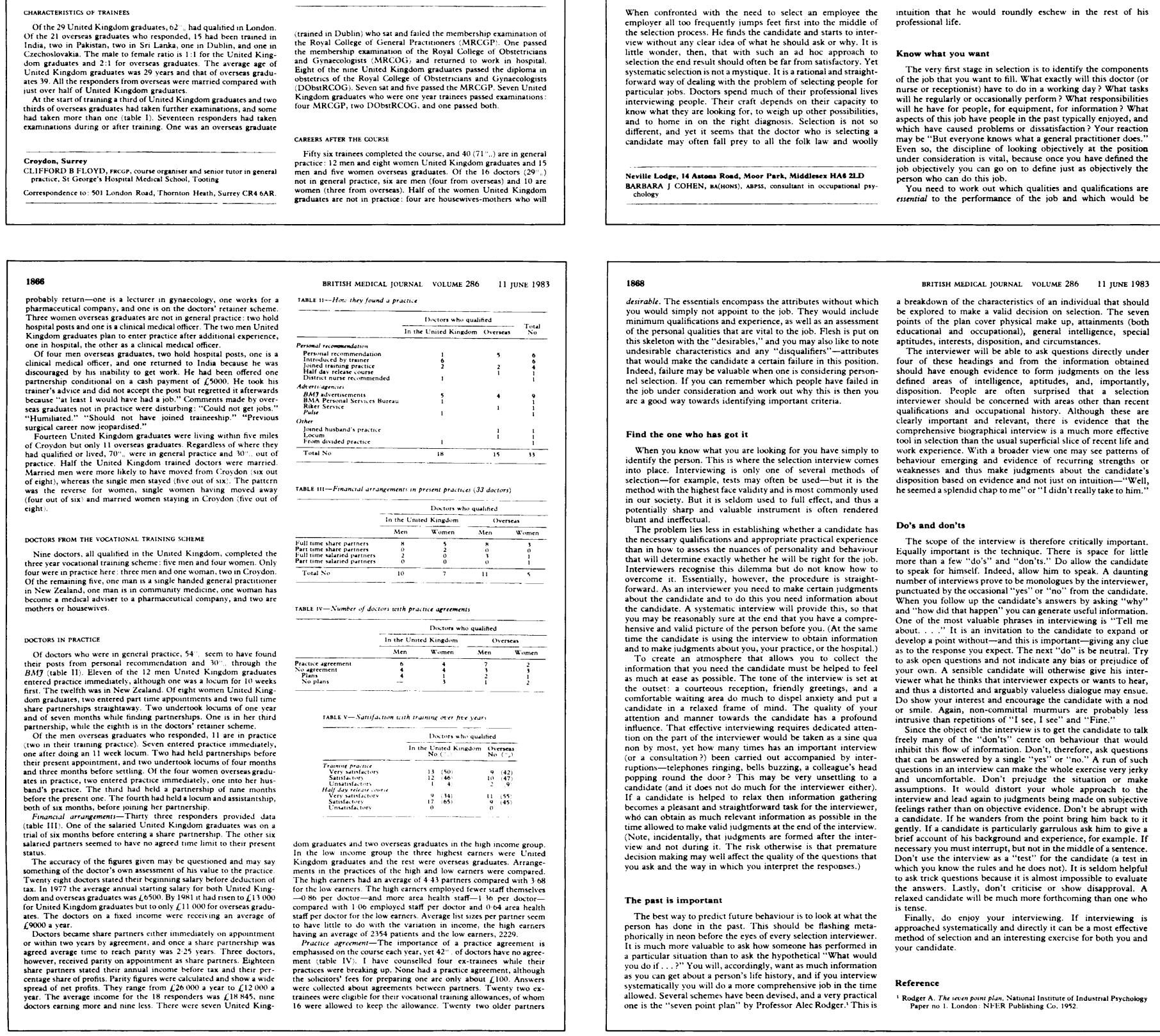

1868

decirable. The essentials encompasss hhe atritibutes without which
you would simply not appoinn to the iob. They would include

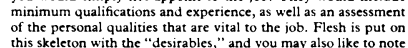

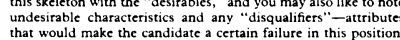
Indeed, failure may be valuable when one is considering pertron.
nel selection.

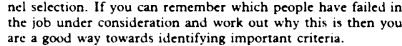

Find the one who has got it

When you know what you are looking for you have simply to
identify hhe person. This is where the selcction intervicu, comes

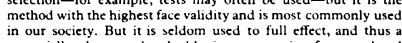

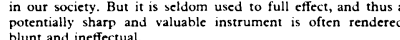

Dlunt and ineffectual
The problem lies less in establishing whecther a candidatc has

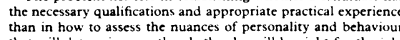

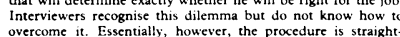

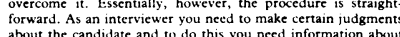

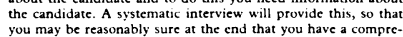

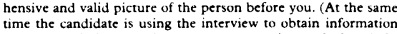

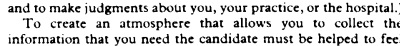

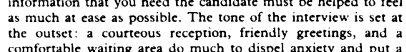

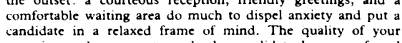

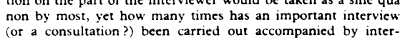

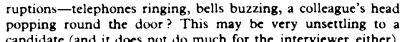
If a candidate is helped to relax then information gathering

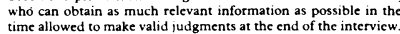

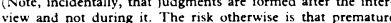

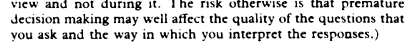

The past is importa

The best way to predict future chavaviur is to look at what the
person has donec in the past. This should be flashing m meta-

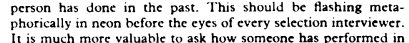

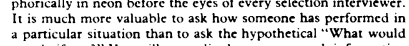

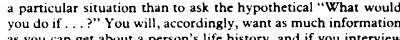

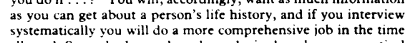

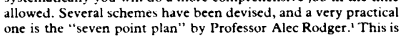

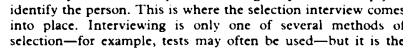

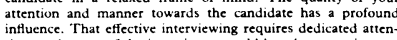

BRRTISH MEDICAL JOCRNALL VOLUME $286 \quad 11$ JUEE 1983

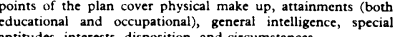

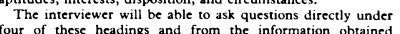

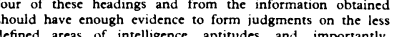

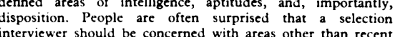

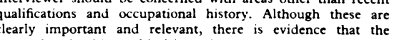

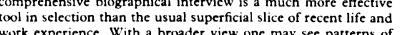

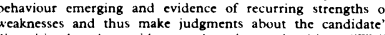

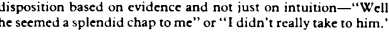
Do's and don'ts

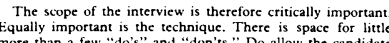

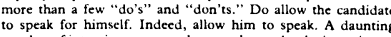

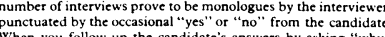

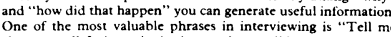

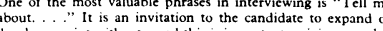
$\begin{array}{ll} & \\ & \end{array}$

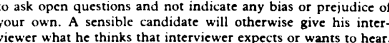

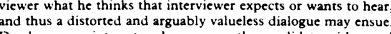

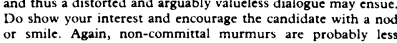

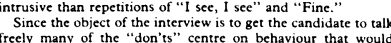
that can be answered by a single "yes"s" or "no." A run of such

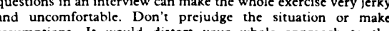

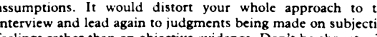
candidate. If he wanders from the point bring him back to

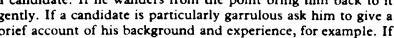

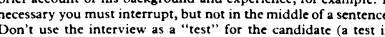

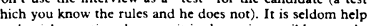

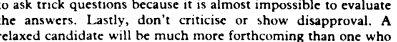

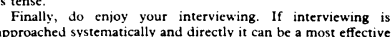

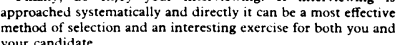

Reference

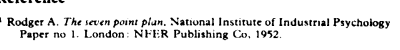
a breakdown of the characteristics of an individual that should
be explored to makce a valid decision on sclection. The seven work experience. With a broader view one may see parterns of

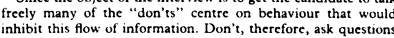

